\title{
More than Shared Love: Does Sharing a Passionate Activity with a Romantic Partner Strengthen the Relationship?
}

\author{
Maylys Rapaport ${ }^{1,2}$ (D) Noémie Carbonneau ${ }^{3}$. \\ Ariane C. St-Louis ${ }^{1,2}$ - Samuel Rochette ${ }^{3}$. \\ Robert J. Vallerand ${ }^{1,2,4}$
}

\begin{abstract}
The Dualistic Model of Passion (Vallerand et al. Journal of Personality and Social Psychology, 85, 756-767, 2003) suggests the existence of two types of passion: harmonious (HP) and obsessive (OP). Previous research in positive psychology has shown that passion can be oriented toward activities, as well as romantic partners, and that both are important for people's well-being and relationships. The purpose of the present research was to integrate these two areas of passion by examining how one's type of passion for a joint activity and for a romantic partner influences the experience of positive and negative emotions during the joint activity, and its impact on the strengthening of the relationship. Results from a path analysis $(N=205)$ revealed that HP for the joint activity and for the romantic partner both positively predicted the experience of positive emotions during the joint activity that, in turn, positively predicted the strengthening of the relationship. Conversely, OP for the joint activity and for the romantic partner both positively predicted the experience of negative emotions during the joint activity that, in turn, negatively predicted the strengthening of the relationship. These findings suggest that these two domains of passion make an important and unique contribution to romantic relationships.
\end{abstract}

Electronic supplementary material The online version of this article (https://doi.org/10.1007/s41042-0180012-8) contains supplementary material, which is available to authorized users.

Maylys Rapaport

maylys.rapaport@gmail.com

1 Laboratoire de Recherche sur le Comportement Social, Montreal, Canada

2 Université du Québec à Montréal, Montreal, Canada

3 Université du Québec à Trois-Rivières, Trois-Rivières, Canada

4 Australian Catholic University, Melbourne, Australia 
Keywords Dualistic model of passion - Romantic passion - Harmonious passion · Obsessive passion $\cdot$ Joint activity $\cdot$ Relationship strengthening

Research in positive psychology has underscored the importance of romantic relationships in people's lives. Couples use different strategies to nurture and strengthen their relationship. Research on romantic relationships shows that one of these strategies is to spend quality time together (Aron et al. 2002; Berg et al. 2001; Kilbourne et al. 1990; Orden and Bradburn 1968; Orthner 1975; Voorpostel et al. 2010; Zuo 1992). One way couples do so is through sharing enjoyable activities, such as travelling, watching movies, playing sports, or gardening. In fact, taking part in such joint activities offers great opportunities for couples to share positive emotions, which should lead to important benefits for their relationship (Aron et al. 2000, 2001; Brehm 1992; Flora and Segrin 1998; Girme et al. 2014; Lawler 2001). Thus, sharing enjoyable activities appears to bring partners closer together and to reinforce their romantic relationship because of the positive emotions that they both experience throughout the joint activity (Kilbourne et al. 1990; Kingston and Nock 1987; Orden and Bradburn 1968; Orthner 1975; White 1983). However, not all joint activities are relationship enhancing (Reissman et al. 1993). Two partners may, for instance, practice a sport together and constantly argue because they are overly competitive. They would then experience negative emotions during the joint activity and sharing this activity would negatively impact their relationship (Segrin and Flora 2005; Walsh et al. 2017). Thus, sharing activities may strengthen relationships but it depends on the way romantic partners engage in their joint activity and on the type of emotions that derives from their joint experience.

Numerous research has shown that passion plays an important role in the way people engage in their passionate activity, as well as in their romantic relationships, and impacts the emotional experience during activity engagement (see Vallerand 2015 for a review). In particular, the Dualistic Model of Passion (DMP; Vallerand et al. 2003) proposes the existence of two types of passion, harmonious and obsessive, that entail a different form of quality engagement in the activity, leading to the experience of positive and negative emotions, respectively. Thus, the DMP seems to offer an interesting framework to investigate how sharing a passionate activity with a romantic partner may affect the experience of emotions during the joint activity and the consequences on the romantic relationship. The purpose of the present research is to examine how one's type of passion for a joint activity and for a romantic partner influence the experience of positive and negative emotions during the joint activity, and their impact on the strengthening of the relationship.

\section{The Dualistic Model of Passion}

Passion is defined as a strong inclination toward a self-defining activity (object, person, or ideology) that one loves, finds important and meaningful, and in which one invests time and energy (Vallerand et al. 2003; Vallerand 2008, 2010, 2015). The DMP suggests the existence of two types of passions, namely harmonious and obsessive passion. 
Harmonious passion (HP) is a motivational tendency that leads individuals to freely and deliberately engage in the beloved activity. HP results from an autonomous internalization of the activity into one's identity (Deci and Ryan 2000). An autonomous form of internalization emanates when a person freely receives the activity as valuable for itself and without any contingencies attached to it. This internalization process originates from the integrated self, meaning that it is in harmony with one's sense of self (Hodgins and Knee 2002; Ryan and Deci 2000). Thus, individuals with a HP toward an activity do not feel an uncontrollable urge to engage in their passionate activity, but rather freely choose to do so. When it comes to HP, behavioral engagement is flexible: individuals are able to decide when to and when not to engage in the passionate activity. Individuals with this type of passion can thus fully concentrate on the task at hand and experience positive outcomes both during and after activity engagement (Vallerand 2015).

On the other hand, obsessive passion (OP) refers to an internal pressure that leads individuals to engage in an activity that one loves. It results from a controlled internalization of the activity into one's identity (Deci and Ryan 2000). A controlled form of internalization instigates from a forced involvement in the activity, with contingencies attached such as self-esteem and social acceptance. In such case, the activity is in discord with one's sense of self and there is conflict among the internalized components. Thus, people with an OP for the activity feel controlled by their passionate activity. They just cannot help but to engage in it. Because the activity becomes out of one's control, it can take disproportionate space in a person's life and lead one to neglect other areas of his or her life, thereby resulting in conflict. Even though individuals with an OP may derive some pleasure from their involvement in the passionate activity, they mostly experience negative cognitive, affective, and behavioral consequences during and after activity engagement (Vallerand 2015).

Although the internalization processes (autonomous or controlled) lead to the initial development of a predominant type of passion, both types of passion are nevertheless present within the individual to different degrees. In fact, different personal or social factors can temporarily trigger one type of passion or another. For example, before a competition, a person with a predominant HP for his or her sport could decide to put other aspects of his or her life aside to fully invest the competition (which is a feature of OP), but will go back to his or her original type of passion once the competition is over. Thus, people have a predominant type of passion but they still have features of both HP and OP and can move from one to another depending on the context.

Empirical support has been provided for the dual perspective on passion (see Vallerand 2008, 2010, 2015 for reviews). For instance, many studies have shown that the two types of passion predict differently a number of intrapersonal and interpersonal outcomes (see Curran et al. 2015; Vallerand 2015 for reviews). Specifically, in terms of intrapersonal outcomes, findings underscored that $\mathrm{OP}$ is positively related to the experience of negative emotions during and after activity engagement (Mageau et al. 2005; Stoeber 2011; Vallerand et al. 2003, Study 1) and is negatively related to indices of subjective well-being (Forest et al. 2011; Lafreniere et al. 2012, 2013; Lalande et al. 2017; Rousseau and Vallerand 2003; Stenseng and Phelps 2013; St Louis et al. 2016; Vallerand et al. 2007, 2008a, b). Conversly, HP has been associated with positive emotions during activity engagement (Carbonneau et al. 2010; Lafrenière et al. 2009; Lee et al. 2013; Mageau et al. 2005; Philippe et al. 2009a; Przybylski et al. 2009; Rousseau 
and Vallerand 2008; Vallerand 2008; Stoeber et al. 2011; Vallerand et al. 2003, 2006), and positively predicts subjective well-being (Forest et al. 2011; Lafreniere et al. 2012, 2013; Lalande et al. 2017; Rousseau and Vallerand 2008; Vallerand et al. 2003, 2007).

Regarding interpersonal outcomes, research has shown that having a HP or an OP toward an activity differently affects the quality of interpersonal relationships both inside and outside of the passionate activity, because of the emotions that are experienced during activity engagement. Firstly, passion for an activity impacts interpersonal relationships that take place in the passionate activity. For instance, a series of studies by Philippe et al. (2010) has shown that OP leads to a decrease in relationship quality with teammates because of the negative emotions that are experienced while practicing the activity. Conversely, HP leads people to easily make new friends when they engage a passionate activity and they develop high quality relationships with other people who engage in the activity because they share positive emotions during activity involvement. In addition, past research has revealed that people with an OP behave more aggressively towards others when practicing their passionate activity than people with a HP (Donahue et al. 2009). Those results were replicated in everyday life situations (Philippe et al. 2009b). Secondly, passion also impacts relationships outside of the passionate activity. For example, OP for online gaming negatively predicts both the number of offline friends that individuals have and the quality of such friendships (Utz et al. 2012). The type of passion developed towards an activity also affects the individual's romantic relationship. For instance, OP for the Internet leads to greater conflict in the romantic relationship and to low levels of dyadic adjustment, whereas HP reveals opposite effects (Séguin-Levesque et al. 2003). Furthermore, research has shown that, contrary to HP, OP for an activity negatively affects the romantic relationship satisfaction because it generates conflicts between the passionate activity and the loved one (Vallerand et al. 2008b). In sum, past findings has uncovered that the type of passion towards an activity not only affects intrapersonal outcomes related to the practice of the activity, such as emotions or well-being, but also impacts relationships within and outside the purview of the passionate activity. It also revealed that emotions served as mediators of such effects.

\section{On Romantic Passion}

In addition to being passionate for a given activity, people are often passionate for another important area of their life: their romantic relationship. In line with Vallerand et al. (2003); Vallerand 2008, 2010), it was proposed that the dualistic conceptualization of passion also applies to romantic involvement. Romantic passion is defined as a strong inclination toward a romantic partner that one loves and with whom one has a relationship that is deemed important and into which one invests significant time and energy (Ratelle et al. 2013). As with passion for activities, two types of romantic passion are proposed. HP refers to a motivational tendency whereby people willingly choose to engage in a romantic relationship with their partner. People autonomously pursue this type of passionate relationship; they don't feel obligated to. Their romantic passion is in harmony with other life domains. Conversely, OP refers to an internal pressure that drives people to pursue a romantic relationship with their beloved partner. With OP, people feel that the passion controls them and that it 
must run its course. This type of passion can create conflicts with other life domains and comes to control the individual.

Previous research has provided support for the validity of the DMP applied to romantic relationships (e.g., Carbonneau et al. 2016; Ratelle et al. 2013). As with passionate activities, findings reveal that the two types of passion differently predict a number of romantic outcomes. Contrary to OP, HP is positively related to the individual's relationship quality, but also to his or her partners' relationship quality (Ratelle et al. 2013). HP also predicts a longer commitment in a romantic relationship than OP (Ratelle et al. 2013). Furthermore, past research has shown that HP positively predicts reparative behaviors following conflict and negatively predicts destructive conflict behavior, whereas OP only positively predicts destructive conflict behaviors (Carbonneau and Vallerand 2013). Thus, it appears that HP for romantic relationships leads to a more peaceful emotional climate in the relationship and to a better relationship quality for both partners.

To summarize, the DMP proposes the existence of two types of passion, HP and OP, that can be oriented toward both activities and romantic relationships. Further, findings uncovered that the HP and OP typically lead to positive and negative personal and relational outcomes, respectively. Importantly, emotions were found to significantly mediate the relationship between passion and outcomes. More specifically, past research revealed that positive emotions mediate the positive effects of HP on intra- and inter-personal outcomes, while negative emotions mediate the effects of OP on intraand inter-personal outcomes.

\section{The Present Research}

As mentioned above, past research has established that the quality of engagement in passionate activities and in romantic relationships differs according to one's type of passion for an activity and to one's type of romantic passion, leading to positive or negative individual and relational outcomes. Importantly, emotions served as mediators of such effects. However, no research has yet been conducted on the combination of passion for an activity and romantic passion. Specifically, we wondered how sharing a passionate activity with one's passionate romantic partner can impact the emotions experienced in the joint activity and their effect on the strengthening of the relationship as a function of the type of passion involved. The purpose of the present research was to address this issue.

The present research proposes that having a HP (either for the joint activity or the romantic relationship) would positively predict the experience of positive emotions during the joint activity, which, in turn, would be positively associated with the strengthening of the relationship. Conversely, it was expected that having an OP (either for the joint activity or the romantic relationship) would induce the experience of negative emotions during the joint activity that, in turn, would be negatively associated with the strengthening of the relationship.

In addition, three control variables were added to our model. Firstly, according to Aron and his colleagues (2000), a major factor that will positively affect the relationship is the level of excitement induced by the activity. Research has provided evidence for an increase of positive emotions (Farber and Hall 2007; Kerr et al. 2006; Legrand 
and Apter 2004; McIntyre and Roggenbuck 1998) and a decrease of negative emotions (Castanier et al. 2011; Kerr et al. 2006; Legrand and Apter 2004) when partners take part in an exciting activity together. Thus, in accordance with past research, it was hypothesized that the level of excitement would be respectively positively and negatively associated with positive and negative emotions during joint activity engagement, and that it would also be positively related to the strengthening of the relationship. Additionally, in line with Aron et al. (2000), it was proposed that the present model should stand while controlling for the level of excitement inherent in the activity. Secondly, because the aim of this study was to assess the strengthening of the relationship following joint activity engagement, important romantic relationship variables from outside of the joint passionate activity, relationship quality and length, were added as controlled variables in the model. This way, the present research allows the assessment of the influence of passion (both for the joint activity and the relationship) on the strengthening of the relationship, and not the influence of other relationship variables from outside of the joint activity. Thus, it was suggested that the proposed model should stand while controlling for both romantic relationship quality and length.

\section{Method}

\section{Participants and Procedure}

Participants were $205^{1}$ French Canadians (150 women, 52 men, 3 missing) currently involved in a romantic relationship. Mean age was 30.83 years $(S D=11.22$ years). The average relationship length was 6 years and 11 months ( $S D=8$ years and 11 months). Regarding relationship status, $23.4 \%$ were married, $55.1 \%$ were living with their partner without being married, and $21.5 \%$ were dating. Participants were recruited on Facebook through an advertisement targeting individuals currently involved in a romantic relationship. The add contained the following information: "We are looking for French Canadian adults who are currently involved in a romantic relationship in order to complete an online survey about activities shared in a romantic relationship. If you are interested, please click on the link below to complete the online survey." Individuals interested in participating in the study were directed to an online survey website that contained the questionnaire.

\section{Instruments}

Demographic Variables Participants completed a demographic information section that included questions on gender, age, number of children, frequency of the activity, relationship status and involvement in a heterosexual or same-sex couple.

Passion for the Joint Activity Participants were asked to identify an activity that they regularly engage in with their partner and that they both love and value deeply. They

\footnotetext{
${ }^{1}$ Statistical power was calculated (alpha $=0.05$; $\mathrm{df}=2$; desired power $=0.80$; RMSEA for $\mathrm{H} 0=0.05$ and RMSEA for $\mathrm{H} 1=0.10$; see www.quantpsy.org), and results revealed that at least 200 participants were needed for the proposed model (Kline 2010).
} 
were then asked to complete the Passion Scale (Marsh et al. 2013; Vallerand et al. 2003) with regard to this joint activity. The Passion Scale consists of two 6-item subscales respectively assessing HP and OP. A sample item for HP is: "This activity is in harmony with other things that are part of me." A sample item for OP is: "I almost have an obsessive feeling for this activity." Responses were scored on a 7-point Likert-type scale ranging from (1) do not agree at all to (7) very strongly agree. In the present study, the Cronbach alpha of both the HP and OP subscales was .86. Strong empirical support exists for the Passion Scale (see Marsh et al. 2013; Vallerand 2015).

Passion for the Romantic Relationship The twelve-item Romantic Passion Scale (Carbonneau and Vallerand 2013; Ratelle et al. 2013) was used to assess romantic HP and OP. A sample item for HP is: "My relationship with my partner is in harmony with other things that are part of me." A sample item for OP is: "I almost have an obsessive feeling for my partner." Responses were scored on a 7-point Likert-type scale ranging from (1) do not agree at all to (7) very strongly agree. In the present study, the Cronbach alphas of the HP and OP subscales were .92 and .85 , respectively.

Positive and Negative Emotions during Joint Activity Engagement Positive emotions (e.g., enthusiastic, determined) and negative emotions (e.g., nervous, hostile) experienced during activity engagement with the partner were each assessed using eight items derived from the Positive and Negative Affect Schedule (Mackinnon et al. 1999) and from Izard's (1997) differential emotional theory (see Philippe et al. 2010, for a similar procedure). Responses were scored on a 7-point Likert-type scale ranging from 1 (not at all) to 7 (very strongly). In the present study, the Cronbach alphas for the positive and negative emotions subscales were respectively .89 and .88 .

Strengthening of the Relationship Six items $(\alpha=.71)$ were used to assess whether participants felt that taking part in the joint activity with their partner had strengthened their relationship with their partner. A sample item is: "To what extent do you feel that engaging in this activity together with your partner has strengthened your relationship?" Responses were scored on a 7-point Likert-type scale ranging from 1 (not at all) to 7 (very strongly).

Excitement towards the Joint Activity Four items $(\alpha=.69)$ were used to assess the inherent level of excitement of the activity shared with the partner. Specifically, participants were asked to indicate to what extent they believe that the activity that they share with their partner is generally "exciting", "boring" (reverse coded), etc. Responses were scored on a 7-point Likert-type scale ranging from 1 (not at all) to 7 (very strongly).

Relationship Quality Relationship quality was assessed with the 6-item $(\alpha=.89)$ short form of the Perceived Relationship Quality Components Inventory (Fletcher et al. 2000). A sample item is: "How satisfied are you with your relationship?". Responses were scored on a 7-point Likert-type scale ranging from 1 (not at all) to 7 (extremely). 


\section{Results}

A model tested how HP and OP for the joint activity and for the romantic relationship would lead to positive and negative emotions during the joint activity, and their impact on the strengthening of the relationship. This model was tested while controlling for the excitement toward the joint activity, the relationship quality and its length. The means and standard deviations of the main variables in the model are reported in Table 1 while correlations among the study variables are presented in Table 2.

The structural equation modeling analyses were performed on the raw data file using maximum likelihood estimation procedure (EQS version 6; Bentler 1989). The proposed model was composed of seven exogenous variables (i.e., HP and OP for the joint activity, HP and OP for the romantic relationship, excitement for the joint activity, relationship quality, and relationship length) and three endogenous variables (i.e., positive and negative emotions during joint activity engagement and the strengthening of the relationship). Paths were drawn based on the hypotheses presented above. Thus, paths from HP and OP for the joint activity, from HP and OP for the relationship, and from excitement toward the joint activity to both positive and negative emotions during the joint activity were specified. Then, paths were drawn from positive emotions and negative emotions during the joint activity and from excitement toward the joint activity to the strengthening of the relationship. Positive and negative emotions were allowed to covary. This model yielded poor fit indices to the data. We thus conducted Wald tests (which identify paths included in the model that can be dropped without reducing model fit) and Lagrange Multiplier tests (which identify paths not included in the model that would significantly improve the model fit).

In line with these tests, a new path analysis was conducted, where paths from HP and OP toward the joint activity, from HP for the relationship, from excitement toward the joint activity, and from relationship quality to positive emotions were specified. Then, paths from OP toward the joint activity, from HP and OP for the relationship, and from excitement toward the joint activity to negative emotions were drawn. Moreover,

Table 1 Means and standard deviations of the main variables

\begin{tabular}{lll}
\hline Variables & Mean & Standard deviation \\
\hline HP for the joint activity & 5.46 & 1.16 \\
OP for the joint activity & 2.77 & 1.55 \\
HP for the romantic relationship & 5.63 & 1.19 \\
OP for the romantic relationship & 3.44 & 1.50 \\
Positive Emotions during joint activity engagement & 5.51 & 1.10 \\
Negative Emotions during joint activity engagement & 1.44 & 0.73 \\
Strengthening of the relationship & 3.98 & 1.78 \\
Excitement towards the joint activity & 3.66 & 2.00 \\
Relationship length & 83.59 months & 107.10 months \\
Relationship quality & 5.96 & 1.03 \\
\hline
\end{tabular}

*The scores indicated in the present Table can be interpretable thanks to the Likert scale used to complete the different measures ranging from "1- Do not agree at all" to "7- Very strongly agree" 
Table 2 Correlations among the study variables

\begin{tabular}{|c|c|c|c|c|c|c|c|c|c|c|}
\hline & (1) & (2) & (3) & (4) & (5) & (6) & (7) & (8) & (9) & $(10)$ \\
\hline (1) HP for the joint activity & _- & $.29^{* *}$ & $.53^{* * *}$ & .05 & $.69^{* *}$ & $-.15^{*}$ & $.58^{* *}$ & $.57^{* * *}$ & -.11 & $.26^{* *}$ \\
\hline (2) OP for the joint activity & & - & .09 & $.36^{* * *}$ & $.28^{* *}$ & $.28^{* *}$ & $.18^{* *}$ & $.30^{* * *}$ & -.03 & .09 \\
\hline (3) HP for the romantic relationship & & & - & $.31^{* *}$ & $.62^{* *}$ & $-.21^{* *}$ & $.58^{* *}$ & $.32^{* *}$ & $-.14^{*}$ & $.67^{* * *}$ \\
\hline (4) OP for the romantic relationship & & & & - & $.20^{* *}$ & $.16^{*}$ & .12 & .01 & $-.20^{* *}$ & $.47^{* *}$ \\
\hline $\begin{array}{l}\text { (5) Positive Emotions during joint } \\
\text { activity engagement }\end{array}$ & & & & & - & $-.20^{* *}$ & $.69^{* *}$ & $.60^{* *}$ & $-.14^{*}$ & $.43^{* *}$ \\
\hline $\begin{array}{l}\text { (6) Negative Emotions during joint } \\
\text { activity engagement }\end{array}$ & & & & & & - & $-.26^{* *}$ & $-.22^{* *}$ & .04 & -.11 \\
\hline $\begin{array}{l}\text { (7) Strengthening of the } \\
\text { relationship }\end{array}$ & & & & & & & - & $.54^{* * *}$ & -.10 & $.47^{* * *}$ \\
\hline $\begin{array}{l}\text { (8) Excitement towards the joint } \\
\text { activity }\end{array}$ & & & & & & & & - & -.05 & $20^{* *}$ \\
\hline (9) Relationship Length & & & & & & & & & - & -.12 \\
\hline (10) Relationship Quality & & & & & & & & & & - \\
\hline
\end{tabular}

**. Correlation is significant at the 0.01 level (2-tailed)

*. Correlation is significant at the 0.05 level (2-tailed)

paths were specified from positive emotions and negative emotions during the joint activity to the strengthening of the relationship. Positive and negative emotions were allowed to covary. Finally, direct paths were drawn from HP for the relationship, from excitement toward the joint activity, and from relationship quality to the strengthening of the relationship. This model had adequate fit to the data. Indeed, the chi-square value was non-significant, $\chi^{2}(d f=9, N=205)=5.23, p=.814$, and other fit indices were excellent: Normed Fit Index $(\mathrm{NFI})=.99$, Comparative Fit index $(\mathrm{CFI})=1.0$, Goodnessof-Fit Index $(\mathrm{GFI})=.99$, Standardized Root Mean Square $(\mathrm{SRMR})=.01$, and Root Mean Square Error of Approximation $(\mathrm{RMSEA})=.00[.00 ; .05]$. The standardized solution of the final model is presented in Fig. 1.

In regard to passion for the joint activity, HP positively predicted positive emotions experienced during joint activity engagement $(\beta=.35, p<.001)$ and OP positively predicted negative emotions $(\beta=.37, p<.001)$. Pertaining to romantic passion, HP positively predicted positive emotions experienced during joint activity engagement $(\beta=.32, p<.001)$ and negatively predicted negative emotions $(\beta=-.17, p<.05)$. Conversely, OP positively predicted negative emotions during joint activity engagement $(\beta=.16, p<.05)$. In turn, positive emotions positively predicted the strengthening of the relationship $(\beta=.26, p<.001)$, whereas negative emotions negatively predicted the strengthening of the relationship $(\beta=-.20, p<.01)$. In addition, as expected, the level of excitement for the shared activity made significant contributions to the prediction of both positive $(\beta=.22, p<.001)$ and negative $(\beta=-.24, p<.01)$ emotions and had a positive direct effect on the strengthening of the relationship $(\beta=.27$, $p<.001)$. Finally, positive direct paths were significant between HP for the relationship and the strengthening of the relationship $(\beta=.16, p<.05)$, and between relationship quality and the strengthening of the relationship $(\beta=.13, p<.05)$. 


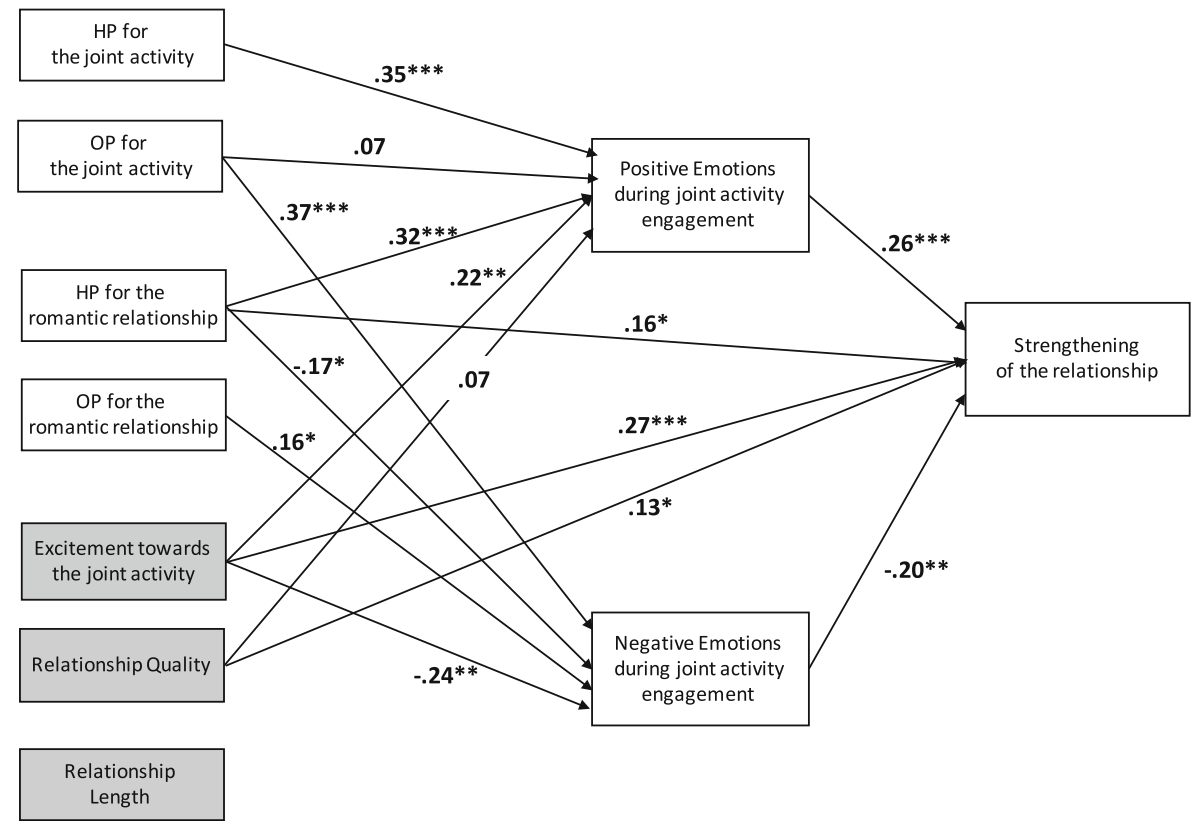

Fig. 1 Structural Equation Modeling of Passion, Emotions and Strengthening of the Relationship. Note. $n=$ $205 ; * p<.05, * * p<.01 ; * * * p<.001$. For sake of clarity, the covariances are not presented in the Figure

\section{Indirect Effects}

Bias-corrected bootstrapped 95\% confidence interval estimates of indirect effects (see (Preacher and Hayes 2008; Shrout and Bolger 2002) were then conducted to confirm the mediating role of positive and negative emotions in the relationships between both passion for the joint activity and romantic passion and the strengthening of the relationship. Bootstrapping is a resampling technique that creates resamples of the same size as the original sample using sampling with replacement. This process is repeated several times, thus providing sample distributions of indirect effects. As a result, indirect effects can be statistically estimated as well as and their $95 \%$ confidence intervals. In the present research, the confidence interval was bias corrected given that this correction is believed to improve power and Type 1 error rates (MacKinnon et al. 2004). As can be seen in Table 3, bootstrap analyses provided support for the mediating role of positive emotions in the relationship between HP (both towards the joint activity and the romantic relationship) and strengthening of the relationship. In addition, negative emotions were found to mediate the relationship between OP (both towards the joint activity and the romantic relationship) and the strengthening of the relationship. The present model was reproduced controlling for different demographic variables. ${ }^{2}$

\footnotetext{
${ }^{2}$ The model proposed in the present research was reproduced controlling for different variables: "having children or not", "number of children", "frequency of the activity", "gender", "relationship status", and "excluding same-sex couples". Same patterns of results were obtained. The reader can contact the first author to have access to those models.
} 
Table 3 Bias-corrected bootstrapped estimates of the mediations

\begin{tabular}{|c|c|c|}
\hline & $\begin{array}{l}\text { Bias-corrected bootstrapped } \\
95 \% \text { confidence interval estimates }\end{array}$ & $p$ value \\
\hline $\begin{array}{l}\text { HP for the activity } \rightarrow \text { Positive Emotions } \rightarrow \text { Strengthening } \\
\text { of the relationship }\end{array}$ & $(.035 ; .165)$ & $<.001$ \\
\hline $\begin{array}{l}\text { OP for the activity } \rightarrow \text { Negative Emotions } \rightarrow \text { Strengthening } \\
\text { of the relationship }\end{array}$ & $(-.123 ;-.006)$ & $<.05$ \\
\hline $\begin{array}{l}\text { HP for the relationship } \rightarrow \text { Positive Emotions } \rightarrow \text { Strengthening } \\
\text { of the relationship }\end{array}$ & $(.050 ; .216)$ & $<.001$ \\
\hline $\begin{array}{l}\text { OP for the relationship } \rightarrow \text { Negative Emotions } \rightarrow \text { Strengthening } \\
\text { of the relationship }\end{array}$ & $(-.079 ;-.004)$ & $<.05$ \\
\hline
\end{tabular}

$n=205$

In sum, the present findings provided support for the proposed model. Globally, controlling for the level of excitement toward the joint activity, the relationship quality and its length, HP toward the joint activity and the relationship lead to the experience of positive emotions during joint activity engagement, which was conducive to the strengthening of the relationship. Conversely, OP toward the joint activity and the relationship was conducive to the experience of negative emotions during joint activity engagement, which, in turn, negatively predicted the strengthening of the relationship. Finally, excitement toward the joint activity positively predicted positive emotions and the strengthening of the relationship, and negatively predicted negative emotions.

\section{Discussion}

The purpose of the present research was to study how HP and OP toward a joint activity and HP and OP toward the romantic relationship affect the emotional experience during the joint activity and the impact on the strengthening of the relationship. It was proposed that, controlling for the excitement toward the joint activity, the relationship quality, and the relationship length, having a HP for both the joint activity and the relationship would lead to the experience of positive emotions while sharing the joint passionate activity. In turn, positive emotions during joint activity engagement should positively predict the strengthening of the romantic relationship. Conversely, it was hypothesized that having an OP for both the joint activity and the relationship would induce negative emotions during joint activity engagement that, in turn, should be negatively associated with the strengthening of the romantic relationship. Finally, it was expected that excitement toward the joint activity would positively and negatively predict positive and negative emotions during joint activity engagement, respectively, would be positively related to the strengthening of the relationship. Overall, these hypotheses were supported and lead to some important implications.

\section{On Passion and Sharing a Passionate Activity in a Romantic Relationship}

Past research has underlined the contribution of passion in many outcomes in both the practice of a passionate activity and the involvement in a passionate romantic 
relationship. The present study was the first to look at the combination of these two areas of passion in the situation of a joint activity. Findings revealed that the emotions experienced during the joint activity differ according to one's type of passion both for the activity and for the romantic relationship, thereby affecting the strenghtening of the relationship. Specifically, results uncovered that having a HP (for both the joint activity and the relationship) is associated with the experience of positive emotions during joint activity engagement that, in turn, lead to the strengthening of the romantic relationship. Conversely, having an OP (for both the joint activity and the relationship) leads to experience negative emotions during joint activity engagement that, in turn, are negatively associated with the strengthening of the romantic relationship. These findings are important for three main reasons, developed below: (1) they specify the unique contribution of both contexts of passion in dyadic functioning, (2) they provide additional support for the role of HP in dyadic functioning, and (3) they provide evidence for the mediating role of emotions during joint activity engagement between passion and its consequences.

First of all, the present findings reveal that both passion for an activity and romantic passion make a unique contribution to the emotional experience during joint activity engagement. Thus, sharing an activity with one's partner has different dyadic consequences depending on the way partners engage in the joint passionate activity and in their romantic relationship. Future research is now needed to test if the effects of passion for an activity and the effects of romantic passion are additive. According to this hypothesis, having two OPs (one for the activity and one for the romantic relationship) would hurt the relationship even more than having simply one. Conversely, having two HPs for both the shared activity and the romantic relationship would lead to even better relationship strengthening than having simply one.

Secondly, the present findings provide additional support for the role of HP in dyadic functioning. Past research has shown that HP provides additional benefits on a host of relational outcomes relative to OP. HP leads to higher friendship and romantic relationship quality (e.g., Philippe et al. 2010; Utz et al. 2012), to a higher relationship length (Ratelle et al. 2013), and to a more adaptive communication than OP (Carbonneau and Vallerand 2013). The present findings are in line with past research and reveal the positive impact of HP, as well as, the detrimental consequences of OP while sharing a passionate activity with a romantic partner on the strengthening of the relationship. Thus, being passionate toward a joint activity and toward one's romantic relationship is not enough, the quality of one's passions also matter. Future research should investigate further the facilitating role of HP in dyadic functioning by exploring different life domains where one's passion can express itself and how to facilitate its development in a harmonious way.

Lastly, the present findings provide strong support for the mediating role of positive and negative emotions during joint activity engagement, in the relationship between passion and dyadic functioning. The mediating effects of emotions between passion and relationships variables have been obtained in many studies from the DMP theory, both in friendships (Philippe et al. 2010) and romantic relationships (e.g., Carbonneau and Vallerand 2013; Vallerand and Carbonneau 2016). The present findings are in line with past research, and underline the major role of emotions in the relationship between passion and the strengthening of the romantic relationship. These findings are important because they indicate that the role of positive and negative emotions is a key to use in 
relationships. It explains how HP and OP influence the beneficial or hurtful effects of engaging in a joint activity with a romantic partner.

\section{On Sharing Time and Romantic Relationship}

Past research has provided support for the importance of sharing quality time with the loved one (Guldner and Swensen 1995; Holman and Jacquart 1988; Kilbourne et al. 1990; Kingston and Nock 1987; Orden and Bradburn 1968; Orthner 1975; White 1983). Sharing pleasing and exciting activities has been shown to positively impact the relationship (Aron et al. 2000). However, the present findings revealed that not all shared activities are relationship enhancing, but that it depends on the type of passionate involvement both in the activity and in the romantic relationship. Indeed, findings uncovered that having an OP (for the activity and for the relationship) will be detrimental for the relationship because of the negative emotions that are induced in the joint activity engagement. However, having a HP (for the activity and for the relationship) will elicit the experience of positive emotions during joint activity engagement, leading to relationship strengthening. These findings are important because they specify how couples can strengthen their relationship. Sharing an exciting activity is not enough, one's passion toward the joint activity and toward the romantic relationship, as well as the emotions experienced in the joint activity matter greatly. In fact, an individual that engages in a joint activity out of an OP will experience negative emotions with his partner, and that will have a negative impact on his relationship. Thus, these findings put in perspective the popular idea that the key to strengthening the relationship is through joint activities. Such positive effects should only take place when the passion for the relationship and the shared activity is harmonious, and permits to experience positive emotions. Thus, the present findings have clinical implications for couples therapy and support. Because sharing an activity with a loved one is positive for the relationship only when it's done out of a HP and when partners have a HP toward the romantic relationship, couple therapists and coaches could advise their clients to share an activity together in order to strengthen their relationship only if the passion for the joint activity and for the romantic passion is harmonious in nature.

Finally, in line with past research (Aron and Aron 1986; Aron et al. 1991, 2000), the present findings underline the role of excitement experienced in the activity on the strengthening of the relationship. Experiencing excitement during joint activity engagement facilitates the experience of positive emotions and decreases the experience of negative emotions. Furthermore, excitement has a positive direct effect on the strengthening of the relationship. Clearly, these findings reinforce the perspective of Aron et al. (2000) that couples should engage in highly exciting activities over less exciting ones. However, the present findings provide a deeper understanding of the processes through which engaging in a joint activity impacts romantic relationships. Indeed, the model proposed in the present study revealed that passion and emotions experienced while engaging in the joint activity influence the strengthening of the relationship above and beyond the excitement of the activity. Thus, couples should not only engage in exciting activities together, they should pursue activities towards which they have a HP, so as to experience positive emotions in their joint practices. 


\section{Limitations and Future Directions}

Despite the potential contributions of this study, it is important to consider the inherent methodological limitations when interpreting the results. First of all, this study assessed only one sample of the population and needs to be replicates. Another limitation pertains to the correlational nature of the study. Even if structural equation modeling analyses were used, it is impossible to formulate causal interpretations of the relations among the model variables assessed in this study because of the correlational design. Future research is needed in order to replicate the present findings using an experimental design. Second, the present study assessed emotions experienced during activity engagement but not those felt after having engaged in the activity. Past research (e.g., Castanier et al. 2011) has shown that emotions can have beneficial consequences after activity engagement. Thus, future research should assess the role of emotions experienced both during and after joint activity engagement in the perception that the joint activity strengthens the relationship. Third, all measures were self-reported, which could have induced social desirability concerns. What an individual perceives will impact how he or she feels and behaves in a situation. However, it would be interesting to replicate our results with more objective measures. Finally, the present research was limited to the assessment of only one member of the couple. It would be important to replicate the present findings using both members' perspective. Is the passion of one member affecting the emotions of the other? And if so, are the interpersonal effects of emotions on the perception of the activity the same as the intrapersonal effects? Future research is necessary to answer these questions.

In sum, the present research contributes to the field of positive psychology as it documents the adaptive role of HP for both an activity and a romantic relationship in the experience of positive emotions during joint activity engagement, and its positive impact on the strengthening of the romantic relationship. In contrary, the results of the present study revealed the detrimental effect of OP (both for the activity and relationship) on the strengthening of the romantic relationship, through the experience of negative emotions during joint activity engagement. It would thus appear that spending time together is not always a perfect strategy to achieve a healthy romantic relationship. However, engaging in a joint activity in which both partners experience a HP for the joint activity and the romantic relationship would appear to be the key in order to strengthen the relationship when spending time together.

\section{Compliance with Ethical Standards}

Conflict of Interest On behalf of all authors, the corresponding author states that there is no conflict of interest.

\section{References}

Aron, A., \& Aron, E. N. (1986). Love and the expansion of self: Understanding attraction and satisfaction. New York: Hemisphere Publishing Corp/Harper \& Row Publishers.

Aron, A., Aron, E. N., Tudor, M., \& Nelson, G. (1991). Close relationships as including other in the self. Journal of Personality and Social Psychology, 60(2), 241-253. 
Aron, A., Norman, C. C., Aron, E. N., McKenna, C., \& Heyman, R. E. (2000). Couples' shared participation in novel and arousing activities and experienced relationship quality. Journal of Personality and Social Psychology, 78(2), 273-284. https://doi.org/10.1037/0022-3514.78.2.273.

Aron, A., Aron, E. N., \& Norman, C. (2001). Self-expansion model of motivation and cognition in close relationships and beyond. Blackwell handbook of social psychology: Interpersonal processes, 478-501.

Aron, A., Norman, C. C., Aron, E. N., \& Lewandowski, G. (2002). Shared participation in self-expanding activities: Positive effects on experienced marital quality. Understanding marriage: Developments in the study of couple interaction, 177-194.

Bentler, P. M. (1989). EQS 6 structural equations program manual (pp. 86-102). Los Angeles: BMDP Statistic Software.

Berg, E. C., Trost, M., Schneider, I. E., \& Allison, M. T. (2001). Dyadic exploration of the relationship of leisure satisfaction, leisure time, and gender to relationship satisfaction. Leisure Sciences, 23(1), 35-46. https://doi.org/10.1080/01490400150502234.

Brehm, S. S. (1992). Intimate relationships. Mcgraw-Hill Book Company.

Carbonneau, N., \& Vallerand, R. J. (2013). On the role of harmonious and obsessive romantic passion in conflict behavior. Motivation and Emotion, 37(4), 743-757. https://doi.org/10.1007/s11031-013-9354-5.

Carbonneau, N., Vallerand, R. J., \& Massicotte, S. (2010). Is the practice of yoga associated with positive outcomes? The role of passion. The Journal of Positive Psychology, 5(6), 452-465. https://doi. org/10.1080/17439760.2010.534107.

Carbonneau, N., Vallerand, R. J., Lavigne, G. L., \& Paquet, Y. (2016). "I'm not the same person since I met you": The role of romantic passion in how people change when they get involved in a romantic relationship. Motivation and Emotion, 40(1), 101-117. https://doi.org/10.1007/s11031-015-9512-z.

Castanier, C., Le Scanff, C., \& Woodman, T. (2011). Mountaineering as affect regulation: the moderating role of self-regulation strategies. Anxiety, Stress \& Coping: An International Journal, 24(1), 75-89. https://doi. org/10.1080/10615801003774210.

Curran, T., Hill, A. P., Appleton, P. R., Vallerand, R. J., \& Standage, M. (2015). The psychology of passion: a meta-analytical review of a decade of research on intrapersonal outcomes. Motivation and Emotion, 39(5), 631-655. https://doi.org/10.1007/s11031-015-9503-0.

Deci, E. L., \& Ryan, R. M. (2000). The" what" and" why" of goal pursuits: Human needs and the selfdetermination of behavior. Psychological Inquiry, 11(4), 227-268. https://doi.org/10.1207/S15327965 PLI1104_01.

Donahue, E. G., Rip, B., \& Vallerand, R. J. (2009). When winning is everything: on passion, identity, and aggression in sport. Psychology of Sport and Exercise, 10(5), 526-534. https://doi.org/10.1016/j. psychsport.2009.02.002.

Farber, M. E., \& Hall, T. E. (2007). Emotion and environment: visitors' extraordinary experiences along the Dalton highway in Alaska. Journal of Leisure Research, 39(2), 248-270.

Fletcher, G. J., Simpson, J. A., \& Thomas, G. (2000). The measurement of perceived relationship quality components: a confirmatory factor analytic approach. Personality and Social Psychology Bulletin, 26(3), 340-354. https://doi.org/10.1177/0146167200265007.

Flora, J., \& Segrin, C. (1998). Joint leisure time in friend and romantic relationships: the role of activity type, social skills and positivity. Journal of Social and Personal Relationships, 15(5), 711-718. https://doi. org/10.1177/0265407598155009.

Forest, J., Mageau, G. A., Sarrazin, C., \& Morin, E. M. (2011). "Work is my passion": the different affective, behavioural, and cognitive consequences of harmonious and obsessive passion toward work. Canadian Journal of Administrative Sciences/Revue Canadienne des Sciences de l'Administration, 28(1), 27-40. https://doi.org/10.1002/cjas.170.

Girme, Y. U., Overall, N. C., \& Faingataa, S. (2014). "Date nights" take two: the maintenance function of shared relationship activities. Personal Relationships, 21(1), 125-149. https://doi.org/10.1111 /pere. 12020 .

Guldner, G. T., \& Swensen, C. H. (1995). Time spent together and relationship quality: long-distance relationships as a test case. Journal of Social and Personal Relationships, 12(2), 313-320. https://doi. org/10.1177/0265407595122010.

Hodgins, H. S., \& Knee, C. R. (2002). The integrating self and conscious experience. In E. L. Deci \& R. M. Ryan (Eds.), Handbook of self-determination research (pp. 87-100). Rochester: University of Rochester Press.

Holman, T. B., \& Jacquart, M. (1988). Leisure-activity patterns and marital satisfaction: a further test. Journal of Marriage and the Family, 50(1), 69-77. https://doi.org/10.2307/352428.

Izard, C. E. (1997). Emotions and facial expressions: a perspective from differential emotions theory. The Psychology of Facial Expression, 2, 57-77. 
Kerr, J. H., Fujiyama, H., Sugano, A., Okamura, T., Chang, M., \& Onouha, F. (2006). Psychological responses to exercising in laboratory and natural environments. Psychology of Sport and Exercise, 7(4), 345-359. https://doi.org/10.1016/j.psychsport.2005.09.002.

Kilbourne, B. S., Howell, F., \& England, P. (1990). A measurement model for subjective marital solidarity: invariance across time, gender, and life cycle stage. Social Science Research, 19(1), 62-81. https://oi. org/10.1016/0049-089X(90)90015-B.

Kingston, P. W., \& Nock, S. L. (1987). Time together among dual-earner couples. American Sociological Review, 52(3), 391-400.

Kline, R. B. (2010). Principle and practice of structural equation modeling (Third ed.). New York: Guilford Press.

Lafrenière, M.-A. K., Vallerand, R. J., Donahue, R., \& Lavigne, G. L. (2009). On the costs and benefits of gaming: the role of passion. Cyberpsychology \& Behavior, 12, 285-290. https://doi.org/10.1016/j. psychsport.2010.08.002.

Lafreniere, M.-A. K., St-Louis, A. C., Vallerand, R. J., \& Donahue, E. G. (2012). On the relation between performance and life satisfaction: the moderating role of passion. Self and Identity, 1-15. https://doi. org/10.1080/15298868.2011.616000.

Lafrenière, M.-A. K., Vallerand, R. J., \& Sedikides, C. (2013). On the relation between self-enhancement and life satisfaction: the moderating role of passion. Self and Identity, 12, 516-530. https://doi.org/10.1080 /15298868.2011.616000.

Lalande, D., Vallerand, R. J., Lafrenière, M. A. K., Verner-Filion, J., Laurent, F. A., Forest, J., \& Paquet, Y. (2017). Obsessive passion: a compensatory response to unsatisfied needs. Journal of Personality, 85(2), 163-178. https://doi.org/10.1111/jopy.12229.

Lawler, E. J. (2001). An affect theory of social exchange. The American Journal of Sociology, 107(2), 321352. https://doi.org/10.1086/324071.

Lee, C. K., Back, K. J., Hodgins, D. C., \& Lee, T. K. (2013). Examining antecedents and consequences of gambling passion: the case of gambling on horse races. Psychiatry Investigation, 10, 365-372. https://doi. org/10.4306/pi.2013.10.4.365.

Legrand, F. D., \& Apter, M. J. (2004). Why do people perform thrilling activities? A study based on reversal theory. Psychological Reports, 94(1), 307-313. https://doi.org/10.2466/pr0.94.1.307-313.

Mackinnon, A., Jorm, A. F., Christensen, H., Korten, A. E., Jacomb, P. A., \& Rodgers, B. (1999). A short form of the positive and negative affect schedule: evaluation of factorial validity and invariance across demographic variables in a community sample. Personality and Individual Differences, 27(3), 405416. https://doi.org/10.1016/S0191-8869(98)00251-7.

MacKinnon, D. P., Lockwood, C. M., \& Williams, J. (2004). Confidence limits for the indirect effect: distribution of the product and resampling methods. Multivariate Behavioral Research, 39(1), 99-128. https://doi.org/10.1207/s15327906mbr3901_4.

Mageau, G. A., Vallerand, R. J., Rousseau, F. L., Ratelle, C. F., \& Provencher, P. J. (2005). Passion and gambling: investigating the divergent affective and cognitive consequences of gambling. Journal of Applied Social Psychology, 35, 100-118. https://doi.org/10.1111/j.1559.

Marsh, H.W., Vallerand, R.J., Lafrenière, M-A.K., Parker, P., Morin, A.J.S., Carbonneau, N., ... Paquet, Y. (2013). Passion: does one scale fit all? Construct validity of two-factor passion scale and psychometric invariance over different activities and languages. Psychological Assessment, 25, 796-809. https://doi. org/10.1037/a0032573.

McIntyre, N., \& Roggenbuck, J. W. (1998). Nature/person transactions during an outdoor adventure experience: a multiphasic analysis. Journal of Leisure Research, 30(4), 401-423.

Orden, S. R., \& Bradburn, N. M. (1968). Dimensions of marriage happiness. The American Journal of Sociology, 73(6), 715-731. https://doi.org/10.1086/224565.

Orthner, D. K. (1975). Leisure activity patterns and marital satisfaction over the marital career. Journal of Marriage and the Family, 37(1), 91-102. https://doi.org/10.2307/351033.

Philippe, F., Vallerand, R. J., Andrianarisoa, J., \& Brunel, P. (2009a). Passion in referees: Examining affective and cognitive experiences in sport situations. Journal of Sport \& Exercise Psychology, 31, 1-21. https://doi.org/10.1123/jsep.31.1.77.

Philippe, F. L., Vallerand, R. J., Richer, I., Vallieres, É., \& Bergeron, J. (2009b). Passion for driving and aggressive driving behavior: a look at their relationship. Journal of Applied Social Psychology, 39(12), 3020-3043. https://doi.org/10.1111/j.1559-1816.2009.00559.x.

Philippe, F. L., Vallerand, R. J., Houlfort, N., Lavigne, G. L., \& Donahue, E. G. (2010). Passion for an activity and quality of interpersonal relationships: the mediating role of emotions. Journal of Personality and Social Psychology, 98(6), 917-932. https://doi.org/10.1037/a0018017. 
Preacher, K. J., \& Hayes, A. F. (2008). Asymptotic and resampling strategies for assessing and comparing indirect effects in multiple mediator models. Behavior Research Methods, 40(3), 879-891.

Przybylski, A. K., Weinstein, N., Ryan, R. M., \& Rigby, C. S. (2009). Having to versus wanting to play: background and consequences of harmonious versus obsessive engagement in video games. Cyberpsychology \& Behavior, 12(5), 485-492. https://doi.org/10.1089/cpb.2009.0083.

Ratelle, C. F., Carbonneau, N., Vallerand, R. J., \& Mageau, G. (2013). Passion in the romantic sphere: a look at relational outcomes. Motivation and Emotion, 37(1), 106-120. https://doi.org/10.1007/s11031-0129286-5.

Reissman, C., Aron, A., \& Bergen, M. R. (1993). Shared activities and marital satisfaction: causal direction and self-expansion versus boredom. Journal of Social and Personal Relationships, 10(2), 243-254. https://doi.org/10.1177/026540759301000205.

Rousseau, F. L., \& Vallerand, R. J. (2003). Le rôle de la passion dans le bien-être subjectif des aînés. = the role of passion in subjective well-being of the elderly. Revue Québécoise de Psychologie, 24(3), 197-211.

Rousseau, F. L., \& Vallerand, R. J. (2008). An examination of the relationship between passion and subjective well-being in older adults. The International Journal of Aging \& Human Development, 66(3), 195-211.

Ryan, R. M., \& Deci, E. L. (2000). Intrinsic and extrinsic motivations: classic definitions and new directions. Contemporary Educational Psychology, 25(1), 54-67. https://doi.org/10.1006/ceps.1999.1020.

Segrin, C., \& Flora, J. (2005). Defining family communication and family functioning. Family Communication, 3-26.

Séguin-Levesque, C., Laliberté, M. L. N., Pelletier, L. G., Blanchard, C., \& Vallerand, R. J. (2003). Harmonious and obsessive passion for the internet: their associations with the couple's relationship. Journal of Applied Social Psychology, 33(1), 197-221. https://doi.org/10.1111/j.1559-1816.2003. tb02079.x.

Shrout, P. E., \& Bolger, N. (2002). Mediation in experimental and nonexperimental studies: new procedures and recommendations. Psychological Methods, 7(4), 422-445.

Stenseng, F., \& Phelps, J. (2013). Leisure and life satisfaction: the role of passion and life domain outcomes. World Leisure Journal, 55(4), 320-332. https://doi.org/10.1080/04419057.2013.836558.

St-Louis, A. C., Verner-Filion, J., Bergeron, C. M., \& Vallerand, R. J. (2016). Passion and mindfulness: accessing adaptive self-processes. The Journal of Positive Psychology, 1-10. https://doi.org/10.1080 $/ 17439760.2016 .124577$.

Stoeber, J. (2011). The dual nature of perfectionism in sports: relationships with emotion, motivation, and performance. International Review of Sport and Exercise Psychology, 4(2), 128-145. https://doi. org/10.1080/1750984X.2011.604789.

Stoeber, J., Harvey, M., Ward, J. A., \& Childs, J. H. (2011). Passion, craving, and affect in online gaming: predicting how gamers feel when playing and when prevented from playing. Personality and Individual Differences, 51(8), 991-995. https://doi.org/10.1016/j.paid.2011.08.006.

Utz, S., Jonas, K. J., \& Tonkens, E. (2012). Effects of passion for massively multiplayer online role-playing games on interpersonal relationships. Journal of Media Psychology. https://doi.org/10.1027/1864-1105 /a000066.

Vallerand, R. J. (2008). On the psychology of passion: in search of what makes people's lives most worth living. Canadian Psychologist, 49, 1-13. https://doi.org/10.1037/0708-5591.49.1.1.

Vallerand, R. J. (2010). On passion for life activities: The dualistic model of passion. In M. P. Zanna (Ed.), Advances in experimental social psychology (Vol. 42, pp. 97-193). New York: Academic Press. https://doi.org/10.1016/S0065-2601(10)42003-1.

Vallerand, R. J. (2015). The psychology of passion: A dualistic model. New York: Oxford University Press, USA.

Vallerand, R. J., \& Carbonneau, N. (2016). The role of passion in optimal relationships. In C. R. Knee \& H. T. Reis (Eds.), Positive approaches to optimal relationship development. Cambridge: Cambridge University Press.

Vallerand, R. J., Blanchard, C. M., Mageau, G. A., Koestner, R., Ratelle, C. F., Léonard, M., ... Marsolais, J. (2003). Les passions de l'âme: on obsessive and harmonious passion. Journal of Personality and Social Psychology, 85, 756-767. https://doi.org/10.1037/0022-3514.85.4.756.

Vallerand, R. J., Rousseau, F. L., Grouzet, F. M. E., Dumais, A., Grenier, S., \& Blanchard, C. M. (2006). Passion in sport: a look at determinants and affective experiences. Journal of Sport \& Exercise Psychology, 28(4), 454 478. https://doi.org/10.1123/jsep.28.4.454.

Vallerand, R. J., Salvy, S. J., Mageau, G. A., Elliot, A. J., Denis, P., Grouzet, F. M. E., \& Blanchard, C. (2007). On the role of passion in performance. Journal of Personality, 75, 505-534. https://doi.org/10.1111 j.1467.6494.2007.00447.x. 
Vallerand, R. J., Mageau, G. A., Elliot, A. J., Dumais, A., Demers, M.-A., \& Rousseau, F. (2008a). Passion and performance attainment in sport. Psychology of Sport and Exercise, 9(3), 373-392. https://doi. org/10.1016/j.psychsport.2007.05.003.

Vallerand, R. J., Ntoumanis, N., Philippe, F. L., Lavigne, G. L., Carbonneau, N., Bonneville, A., ... \& Maliha, G. (2008b). On passion and sports fans: a look at football. Journal of Sports Sciences, 26(12), 1279-1293. https://doi.org/10.1080/02640410802123185.

Voorpostel, M., van der Lippe, T., \& Gershuny, J. (2010). Spending time together-changes over four decades in leisure time spent with a spouse. Journal of Leisure Research, 42(2), 243.

Walsh, C. M., Neff, L. A., \& Gleason, M. E. J. (2017). The role of emotional capital during the early years of marriage: why everyday moments matter. Journal of Family Psychology, 31(4), 513-519. https://doi. org/10.1037/fam0000277.

White, L. K. (1983). Determinants of spousal interaction: marital structure or marital happiness. Journal of Marriage and the Family, 45(3), 511-519.

Zuo, J. (1992). The reciprocal relationship between martial interaction and marital happiness: a three-wave study. Journal of Marriage and the Family, 54(4), 870-878. https://doi.org/10.2307/353168. 